\title{
Las imágenes de las víctimas del conflicto armado en la revista Semana: políticas, significados culturales y visibilización*
}

\section{Dixon Vladimir Olaya Gualteros ${ }^{1}$}

Recibido: 05/09/2018

Aprobado por pares: 27/11/2018
Enviado a pares: 21/09/2018

Aceptado: 10/02/2019

DOI: $10.5294 /$ pacla.2020.23.1.6

Para citar este artículo / to reference this article / para citar este artigo Olaya, D. V. (2020). Las imágenes de las víctimas del conflicto armado en la revista Semana: políticas, significados culturales y visibilización. Palabra Clave, 23(1), e2316. DOI: https://doi.org/10.5294/pacla.2020.23.1.6

\section{Resumen}

El artículo analiza el modo en que fueron visibilizadas las víctimas a través de algunas publicaciones de la revista Semana. Se estudia cómo las imágenes, en correlación con textos periodísticos, coadyuvan en la construcción un régimen visual que contiene y refuerza la noción que de los sujetos víctimas es identificable en la Ley 975/2005, de 25 de julio y la Ley 1448/2011, de 10 de junio. Al tiempo, se sugiere que dichas imágenes interpelan a los espectadores desde lo simbólico-sensible, por lo que se constituyen en dispositivos de formación para la comprensión y narración del conflicto en Colombia. En pro de lo enunciado, se analizan algunos de los temas y de los discursos que con respecto a las víctimas circularon entre 2010 y 2014. Se estudian los componentes morfológicos de las imágenes en relación con los artículos que las acompañan, y se identifican sus relaciones con los significados culturales de la época. El artículo concluye que las imágenes que

\footnotetext{
* Este artículo es parte de los resultados del trabajo de investigación denominado Formación de la mirada y regímenes visuales de la violencia política en Colombia, identificado con el código DPG-435-16, financiado por el Centro de Investigación de la Universidad Pedagógica Nacional.

1 https://orcid.org/0000-0002-3935-3271. Universidad Pedagógica Nacional, Colombia. vlado2380@gmail.com
} 
se refieren a las víctimas dan un alto valor a lo sensible como móvil para la significación de lo político, la guerra y lo humano, pero desde allí también se constituyen visibilidades que hablan del horror y son inmovilizadoras. A través de los artículos y las fotografías se construye una visibilidad de las víctimas que coadyuva a que se planteen relaciones estáticas e identidades suspendidas. Además, sitúan los acontecimientos en un peligroso presentismo que construye un marco de interpelación para los espectadores que los conduce a reconsiderar y construir ciertas significaciones ideológicas.

\section{Palabras clave (Fuente: tesauro de la Unesco)}

Fotografía; violencia política; damnificado de guerra; víctimas; políticas; subjetividad; Colombia. 


\section{Pictures of Victims of the Armed Conflict in Semana: Politics, Cultural Meanings, and Visibility*}

\section{Abstract}

This article discusses how victims were made visible by some publications of the magazine Semana. It examines how images, in correlation with journalistic texts, contribute to building a visual regime that contains and reinforces the notion of victim identifiable in Law 975 of July 25, 2005 and Law 1448 of June 10, 2011. It is suggested that such images address viewers from a symbolic-sensitive perspective, thus becoming formative devices to understand and narrate the Colombian conflict. For this purpose, some of the themes and discourses on victims that circulated between 2010-2014 are analyzed. The morphological components of images are studied in relation to their accompanying articles, and their relationships with the cultural meanings of the time are identified. It is concluded that pictures of victims place a high value on sensitivity as incentive for the significance of politics, war and humanity, but also create visibilities that speak of horror and are immobilizing. Articles and photographs spotlight victims in a way that helps to establish static relationships and suspended identities, while putting events in a dangerous presentism that appeals to spectators to reconsider and construct certain ideological meanings.

\section{Keywords (Source: Unesco Thesaurus)}

Photography; political violence; war victim; victim; politics; subjectivity; Colombia.

* This article is part of the results of the research project called Educating the Eye and Visual Regimes of Political Violence in Colombia, identified by code DPG-435-16 and funded by the Universidad Pedagógica Nacional Research Center. 


\section{As imagens das vítimas do conflito armado na revista Semana: políticas, significados culturais e visibilização*}

\section{Resumo}

Este artigo analisa o modo como as vítimas foram visibilizadas por meio de algumas publicações da revista Semana. É estudado como as imagens, em correlação com textos jornalísticos, contribuem para construir um regime visual que contém e reforça a noção de sujeitos vítimas identificada na Lei 975/2005, de 25 de julho, e na Lei 1.448/2011, de 10 de junho. Em paralelo, sugere-se que essas imagens interpelem os espectadores a partir do simbólico-sensível, por se constituírem em dispositivos de formação para compreender e narrar o conflito na Colômbia. Para atingir o objetivo deste artigo, são analisados alguns dos temas e dos discursos que, a respeito das vítimas, circularam entre 2010 e 2014. São estudados os componentes morfológicos das imagens em relação aos artigos que as acompanham e são identificadas suas relações com os significados culturais da época. Este artigo conclui que as imagens que se referem às vítimas dão um alto valor ao sensível como móvel para a significação do político, da guerra e do humano; contudo e a partir disso, também se constituem visibilidades que falam do horror e são imobilizadoras. Por meio dos artigos e das fotografias, é construída uma visibilidade das vítimas que contribui para que relações estáticas e identidades suspensas sejam apresentadas. Além disso, são situados os acontecimentos em um perigoso "presenteísmo" que produz um contexto de interpelação para os espectadores que os leva a reconsiderar e construir certas significações ideológicas.

\section{Palavras-chave (Fonte: tesauro da Unesco)}

Fotografia; violência política; vítima de guerra; vítimas; políticas; subjetividade; Colômbia.

\footnotetext{
* Este artigo faz parte dos resultados do trabalho de pesquisa denominado "Formación de la mirada y regímenes visuales de la violencia política en Colombia" ("Formação do olhar e regimes visuais da violência política na Colômbia), identificado com o código DPG-435-16, financiado pelo Centro de Pesquisa da Universidad Pedagógica Nacional.
} 


\section{Introducción}

Colombia, después de décadas de violencia, ha iniciado una serie de diálogos con grupos guerrilleros y paramilitares en pro de dar fin al conflicto armado del que han sido víctimas millares de colombianos. En este contexto, la figura de la víctima ha emergido en el escenario político gracias a la promulgación de la Ley 975/2005, de 25 de julio y de la Ley 1448/2011, de 10 de junio, pero a su vez por los agenciamientos de colectivos en defensa de los derechos humanos, diversos emprendimientos de memoria, así como por los medios de comunicación a través de reportajes, informes y seriados que proponen una serie de significaciones en torno a estos. Tales enunciados han coadyuvado a la construcción de prácticas sociales, así como a los modos de identificación tanto para los sujetos afectados por hechos atroces como para aquellos que no han sido perjudicados en su corporalidad.

Ahora bien, los discursos y las imágenes sobre las víctimas dicen, por un lado, de la pugna por una serie de capitales culturales y memorias sobre nuestro pasado reciente, pero, por otro, también hablan de los victimarios, de las dinámicas de la guerra y de las razones del conflicto. En este sentido, las formas en que son nombradas y visibilizadas las víctimas son el resultado de diversos modos de comprensión del conflicto. No obstante, no se puede hablar de discursos y visibilidades absolutamente inconexas. Los semas que tenemos de las víctimas se encuentran en interrelación con otras discursividades que se imbrican y resisten mutuamente, que responden a diferentes espacialidades y temporalidades, pero, a su vez, permiten la constitución de marcos de interpretación para comprender-nos y juzgarnos frente al conflicto armado.

Desde esta óptica, tanto las discursividades como las visibilidades no solo dicen de una serie de disputas semánticas o de representación, sino que nos permiten entender la forma en que el lenguaje, en muchas ocasiones, resulta casi indiferenciable del cuerpo humano (Das, 2008). Así, el acto de desplegar significaciones se constituye en expresión performativa, en un marco de inteligibilidad de los sucesos dados en el momento presente y en que son evidentes una serie hechos políticos y jurídicos. 
Sin embargo, la construcción de una idea de víctima, de su visibilización en el campo social, como lo argumentan Herrera y Pertuz (2015), no dependen tan solo de una coyuntura nacional, sino que obedecen a una serie de articulaciones con políticas internacionales con respecto a la memoria. De hecho, se puede plantear que la concepción de víctima, en sus inicios, en el escenario internacional, "hizo énfasis en el individuo, el sufrimiento, desdibujando los móviles históricos y las dimensiones políticas y sociales de la victimización" (p. 916). En esta misma línea de análisis, Herrera y Pertuz sostienen que la concepción de este tipo de sujeto tuvo su génesis en la serie de tramitaciones y nombramientos sobre el fenómeno del Holocausto. En un segundo momento, el testimonio de las víctimas y, en consecuencia, su emergencia en el escenario de lo público tuvo relación con la transgresión de los derechos humanos y del derecho internacional humanitario. Concepción que no se encuentra desligada de una visión cara a la perspectiva neoliberal en la que prima la individualización y la que desliga a los sujetos de sus identidades colectivas y trayectos históricos.

Sumado a lo anterior, se puede plantear que la configuración del sujeto víctima, en su relación con el testimonio y la memoria, no solo proviene de políticas públicas, sino que ella tiene que ver, en la década de 1960, tanto en Europa como en América Latina, como lo expresa Huyssen (2001), con la búsqueda de historias alternativas resultado de procesos de descolonización y con la emergencia de nuevos movimientos sociales que indagaban otras formas de registrar el pasado que resistiera a una serie de relatos hegemónicos.

Por su parte, Hartog (2012) plantea que la emergencia del sujeto víctima, en los actuales contextos, desvela una preponderancia de un tiempo presente, en tanto las narrativas de los testigos-víctimas se caracterizan por la exposición de la experiencia, por lo que desalojan el discurso histórico. En este orden de ideas, se "reivindica" el trauma y la víctima es "reconocida", pero, a la vez, ello incide en una visión del sujeto en la que este se encuentra postrado en el dolor.

En este contexto, es imposible negar la influencia de los medios de comunicación en la masificación y construcción del sujeto víctima. Recordemos con Huyssen (2001) que es imposible hablar hoy de memoria, 
de víctimas y de victimarios sin tener en cuenta la fuerte presencia de los medios de comunicación como vehículos que hacen circular narrativas en torno a nuestro pasado reciente y las cuales llevan incorporados construcciones éticas, estéticas y políticas de los modos de percibir los hechos traumáticos que se encuentran ligados, además, a procesos de mercantilización y espectacularización de los fenómenos sociales.

En esta perspectiva, es bueno advertir que en Colombia, a pesar del emprendimiento de diálogos de paz con diferentes grupos armados, la discusión sobre las razones de la violencia no es unívoca, ni existe claridad acerca de la manera de contar nuestro pasado violento y mucho menos certezas acerca del tipo de tratamiento a dar a las víctimas en el escenario público. Tal escenario se ha convertido en caldo de cultivo para que transiten diferentes versiones e imágenes de las víctimas y de los victimarios. En esta pugna por los sentidos de la violencia, los medios de comunicación han tenido un papel relevante, pues la forma en que se visibilizan las víctimas cobra una vital importancia en la manera en que en el escenario público no solo se recuerda un pasado violento, sino que se tejen narrativas acerca de los móviles de la violencia. Dichas narrativas han incidido no solo en el escenario cotidiano, sino que trascienden en el modo en que se discute y aprueban prácticas políticas y culturales.

Sumado a ello, los medios de comunicación, en tanto empresas, propiedad de grandes emporios económicos, nacionales e internacionales, relacionadas, en muchos de los casos con sectores del poder político, juegan sus intereses en la visibilización del pasado y de las víctimas, pues ello tiene consecuencias en los modos en que se legitiman o deslegitiman los grupos en el poder y de quienes por él pugnan, lo que coadyuva a la construcción de un régimen visual del conflicto.

\section{Leyes de víctimas y constitución de subjetividad}

El año 2010, para Colombia, estuvo cargado de hechos que desatarían un nuevo orden político en el país, pues el Gobierno del presidente Álvaro Uribe Vélez estaba por finalizar, sin tener la posibilidad de que se diera la tan buscada segunda reelección. La nueva contienda electoral tendría 
como resultado el inicio del mandato presidencial de Juan Manuel Santos. Para algunos, la iniciación de este nuevo Gobierno marcaría la finalización de lo que se denominó la Política de Defensa y Seguridad Democrática, en que las guerrillas del país, bajo la nominalización de terroristas, por parte del Gobierno, fueron el principal objetivo militar.

El Gobierno del presidente Uribe se puede caracterizar por una gran cantidad de masacres en todo el país y que, según cifras del Centro Nacional de Memoria Histórica (CNMH, s. f.), sus efectos ascendían a más 2170 muertes. A su vez, se presentaron más de 46 atentados terroristas con una cifra que sobrepasa las 150000 víctimas fatales y los 900000 lesionados. Sumado a ello, la Unidad de Víctimas (2019) reporta en el periodo de la Política de Defensa y Seguridad Democrática una cifra de 3900000 expulsados de sus territorios, efecto del conflicto armado. Con lo anterior queremos evidenciar que el periodo estuvo signado por la guerra y por generar la condición de víctimas a millones de colombianos, lo que edificó una suerte de identidad colectiva, pues la situación en que se encontraban muchos ciudadanos era presentada ante la sociedad como sujetos con una serie de características específicas e, incluso, con una reputación particular, no deseable.

Sin embargo, es para el periodo del Gobierno Uribe que se promulga la Ley 975/2005, de 25 de julio, que pone en el escenario público el derecho de las víctimas. De hecho, el objetivo fundamental de la ley es "facilitar los procesos de paz y la reincorporación individual o colectiva a la vida civil de miembros de grupos armados al margen de la ley, garantizando los derechos de las víctimas a la verdad, la justicia y la reparación”. La promulgación de tal ley buscaba, según distintos agentes políticos, la reconciliación, lo que permitiría tanto el discurso gubernamental como el de las víctimas y los victimarios, pese a los trágicos hechos. Sin embargo, la concepción que de víctima podemos encontrar en esta ley se puede definir como excluyente. Si bien se caracteriza jurídicamente la víctima, no se tiene en cuenta a quienes fueron y son afectados por crímenes de Estado. Este tipo de sustracción no solo borra a un sujeto, sino que niega al Estado como actor del conflicto. De hecho, muchas organizaciones en defensa de los derechos humanos han insistido en que dicha ley tan solo privilegia a los victimarios y que en realidad no reconoce a las víctimas. 
Sumado a lo anterior, se puede establecer que la víctima, en la Ley $975 / 2005$, de 25 de julio, es concebida como un sujeto pasivo, receptor de ayuda y no necesariamente un sujeto político con una perspectiva de los sucesos y con la posibilidad de agenciamientos en lo social. Mientras tanto, la organización militar del Estado y sus integrantes, pese a ser agentes activos del conflicto, también son entendidos como víctimas, en el mismo reglón que aquellos que sin participar en el conflicto fueron afectados por hechos de violencia. En este sentido, enuncia:

Igualmente se considerarán como víctimas a los miembros de la Fuerza Pública que hayan sufrido lesiones transitorias o permanentes que ocasionen algún tipo de discapacidad física, psíquica y/o sensorial (visual 0 auditiva), o menoscabo de sus derechos fundamentales, como consecuencia de las acciones de algún integrante o miembros de los grupos armados organizados al margen de la ley. (art. 5)

Como es posible deducirlo, mientras el Estado se constituye en agente garante, por fuera de los hechos atroces, las víctimas no son diferenciables. Tal enunciación de las víctimas la constituyen en un sujeto homogéneo como si se tratara, en Colombia, de un solo tipo de violencia y de un solo agente del conflicto, con la que se desconoce, en gran medida, las causas históricas de la violencia. En este orden, se construye un discurso que nominaliza a las víctimas, pero no necesariamente las reconoce en sus experiencias y construcciones.

Con el inicio del Gobierno de Santos, también se da una serie de hechos tanto militares como políticos que visibilizarían a las víctimas en relación con diferentes agentes del conflicto. En el inicio de la Presidencia de Santos en 2010, tiene lugar la baja del comandante de las Fuerzas Armadas Revolucionarias de Colombia (FARC), Jorge Briceño, alias "el Mono Jojoy", en una operación militar denominada Sodoma, que afectó de manera importante a la estructura guerrillera. Esta baja fue antecedida de la muerte de Tiro fijo y Raúl Reyes, dirigentes de la agrupación guerrillera en su momento. Para 2011, también es abatido Alfonso Cano, quien había asumido, después de la muerte del Mono Jojoy, el liderazgo de la guerrilla más antigua de América Latina. Con esta serie de golpes a las FARC, se vaticinaba la terminación del conflicto. 
En este contexto, se da el inicio de las mesas de diálogo con las FARC. Al tiempo, se instaura la Ley 1448/2011, de 10 de junio. En ella se conciben las condiciones jurídicas para la restitución de tierras en pro de aquellos que habían sufrido su despojo por parte de alguno de los grupos armados. De esta forma, dicha ley constituye un nuevo universo de víctimas. En ella se las define como "aquellas personas que individual o colectivamente hayan sufrido daño por hechos ocurridos a partir del $1^{\circ}$ de enero de 1985, como consecuencia de infracciones al Derecho Internacional humanitario o de violaciones graves y manifiestas a las normas internacionales de Derechos Humanos ocurridas en ocasión del conflicto armado interno" (art. 3).

La enunciación política no solo refuerza un tipo de víctima, relacionado con el daño, sino que fortalece las exclusiones que se presentaron en la Ley 975/2005, de 25 de julio. A su vez, esta ley, igual que la anterior, descarta de la reparación a aquellas personas que fueron objeto de vejámenes por parte del paramilitarismo. Son reconocidas por el Gobierno tan solo como afectadas por la delincuencia organizada, por lo que crean un halo que sustrae del conflicto político y armado a los paramilitares. Según ONG como Movimiento Nacional de Víctimas de Crímenes de Estado (Movice) o la Corporación Jurídica Libertad (CJL), en el planteamiento de la ley no se tuvieron en cuenta las voces de quienes serían sus destinatarios, por lo que la norma constitucional se convirtió en una política inconsulta que niega a quienes habían sido afectados por las violencias.

En este contexto, medios de comunicación como la revista Semana hacen circular en el escenario público una serie de imágenes que coadyuvan a construir una idea de víctima, mucho más anclada al dolor que a la vida, por una parte, y por otra, las víctimas se convierten en un instrumento para legitimar el papel del Gobierno y una invisibilización del victimario, en algunos casos, pero en otras constituyéndolo a través de su animalización, lo que despoja la posibilidad de una discusión de las razones políticas de la violencia. Con lo anterior, queremos plantear que las imágenes visuales que fueron extendidas por los medios de comunicación integraban, para su composición, los discursos que desde la política pública se edificaba para la construcción de la víctima desde lo que podemos llamar una afectación desde lo simbólico-sensible. 


\section{Las imágenes fotográficas: entre lo simbólico y lo sensible}

Mirzoeef (2015) nos alienta a pensar la manera en que una fotografía del globo terráqueo, realizada en 1972, por el astronauta Jack Schmitt, a bordo de la nave espacial Apolo 17, no solo actuó como un modo de representación del mundo y el universo, sino que ella posibilitó la creencia de que el mundo era perfectamente cognoscible. De hecho, apunta Mirzoeef que, para muchos, tal fotografía "habría cambiado su vida". En esta perspectiva, la imagen fotográfica dice de la construcción de una relación con aquello visto, un modelo mental de visión.

No obstante, aquello que vemos a través de la fotografía es el resultado del entrecruzamiento de saberes y experiencias adquiridas en diferentes espacios de socialización y en momentos históricos y políticos particulares. Así, habría que indicar que lo visual tiene que ver con formas de involucramiento, de relacionarnos con un sistema cultural. Pero ello no quiere decir que ver sea en sí mismo creer (Mirzoeff, 2015). Ver está relacionado con conducir la mirada hacia un horizonte de sentido que contiene una perspectiva ética, posible de ser resignificada.

Lo anterior es dable si comprendemos que la fotografía constituye un constructo de veracidad. Ella contiene un halo de realidad en el que se impone algún tipo de distancia con lo real, con lo figurado en la fotografía, y que nos ayuda a construir un modo de comprender al otro que se instala entremezclado con una serie de circunstancias sociales y discursividades de todo tipo. En este sentido, la función de la fotografía no consiste, solo, en proponer algún tipo de placer, sino en "ofrecer verdades visuales sobre el mundo" (Fontocuberta, 2002), en las que volcamos una serie de valores y sentidos que generan diversos vínculos. Así, la fotografía se convierte en una suerte de mediación entre lo que somos y el mundo visto y experienciado que no está desligado de las intenciones éticas y políticas del fotógrafo, pero tan poco del medio portador de las imágenes. Las imágenes fotográficas movilizan formas de lo simbólico y lo cultural desde las que es posible identificar valoraciones acerca de lo bueno y de lo malo, de lo trascendente e intrascendente, por lo que configuran regímenes de verdad (Foucault, 1992). 
De acuerdo con lo expuesto, al situar una imagen en la esfera pública, estamos asistiendo no solo a una proliferación de una imagen, sino a la espectacularización de un tipo de relación planteada a través de esta. No obstante, la forma en que interpela la imagen no reside solo en el nombramiento y en la reproducción de una serie de eventos, sino en la posibilidad que tiene la imagen de conjugar lo sensible y lo inteligible, la esperanza y el recuerdo, lo otro y el sí mismo. Además, se refiere a elementos que la visión particular, cotidiana, no puede captar. En este orden de ideas, otorgan una visibilidad que es imposible a través de otros dispositivos, por lo que constituyen la supuesta evidencia de una existencia real que de alguna manera confiere sentido y comprensibilidad al sujeto espectador, pues establece conexiones entre lo visto y los referentes culturales que él sujeto reconoce, más allá de lo imaginado. Así, la imagen fotográfica sirve como mediación, es decir, como producción de una interrelación de elementos dispares (Yepes, 2014).

Ahora bien, creemos que la imagen fotográfica también interpela a los sujetos a través de la estesis, esto es, "la sensibilidad o condición de abertura, permeabilidad o porosidad del sujeto al contexto en que está inmerso" (Mandoki, 2006, p. 67). Lo anterior dado que la imagen no solo contiene información, sino que ella instala una supuesta presencia veraz del pasado en el momento presente, mucho más real que otras formas de lenguaje, pues lo icónico pronuncia y visibiliza un tiempo y un espacio, configura un acontecimiento y propone la construcción de una experiencia en el espectador. Esta experiencia conlleva ejercicios en los que a los individuos les es necesario plantear o recomponer algún tipo de relación con el mundo. Recordemos que la experiencia, según los planteamientos de Dewey (2008), tiene que ver con el intercambio de los sujetos con su medio ambiente físico y social, y no tan solo un problema de conocimiento. Esto es, las relaciones que los sujetos establecen con su entorno posibilitan la constitución de una serie de sentidos alrededor de lo vivido y que se desarrollan a partir de lo sensible, de la percepción. Para ello, los sujetos ponen en juego sentidos y códigos históricamente construidos y los confronta con el objeto y la relación planteada. Lo anterior expone la forma en que lo social juega en la dación de sentido, pero al tiempo la condición individual construye significado al encontrar formas de acoplamiento entre aquello expuesto y el re- 
gistro de experiencias y construcciones simbólicas pasadas. La memoria sensible del sujeto, su repertorio cultural, posibilita tanto la apropiación como la adherencia a ciertas construcciones culturales. En esta perspectiva, la interpelación que busca la elaboración visual pretende construir un tipo de enunciación que incida en la sensibilidad del espectador, a partir de un acercamiento a la experiencia de los sujetos, pues ello les posibilita algún tipo de eficacia en la pugna por los sentidos sociales. Ahora bien, la permeabilidad del sujeto está inscrita en los grados de referencialidad, adherencia, en relación con los niveles de afectividad, pues, como lo plantea Mandoki (2006), los seres humanos solicitamos algún nivel de prendamiento, entendido este como una actividad de involucramiento que implica intencionalidad, una pulsión hacia algo. No obstante, existe por parte del ser humano una actividad de prendimiento, concebido como "encierro y estrechez de la subjetividad en su impotencia, cuando la sensibilidad no es cautivada sino capturada" (p. 89). En este sentido, siguiendo a la investigadora de la estesis, la comunicación no solo transfiere información del emisor al receptor, sino que lo hace de modo persuasivo, cautivador: lo captura. "No solo pretende informar y convencer, sino fascinar" (p. 92).

En este contexto, planteamos que, en medio de la violencia armada, las imágenes de las víctimas vehiculizadas a través de la revista Semana, no solo pugnan por su sentido e identidad, sino que apelan a un tipo de sensibilidad que obnubila e intenta atrapar e interpelar al espectador a partir de una serie de códigos culturales compartidos.

\section{El análisis de las imágenes de la revista Semana}

La investigación denominada Formación de la mirada y regímenes visuales de la violencia política en Colombia, de la cual emerge este artículo, seleccionó, para su estudio, artículos e imágenes de la revista Semana desde 2010 hasta 2014, por dos razones: la primera está relacionada con su larga trayectoria. Esta publicación fue fundada en 1946 y circuló hasta 1961. Su segunda etapa inicia en 1982. Lo anterior la ubica como una de las publicaciones de más larga trayectoria en el país, que completa más de medio siglo de existencia entre sus dos etapas. La segunda razón está relacionada con su nivel de circulación. Según las encuestas de medios, realizadas periódicamente por la Asociación para la Investigación de Medios de Comunicación (AIMC), 
revista Semana, en los últimos diez años, aparece entre el tercer y cuarto puesto de las revistas más leídas, superada tan solo por medios de comunicación dedicados a noticias de moda y farándula ("Audiencia general de medios", s. f.). En este sentido, es posible señalar que, entre las revistas de opinión, la revista Semana es la de mayor circulación en Colombia. Tanto su tradición como su circulación la han situado como un referente importante para la opinión pública y la configuración de sentidos y memorias sobre los aconteceres del país.

El análisis realizado a las imágenes acerca de las víctimas y de los victimarios, contenidas en la revista Semana, parte de comprender, como lo plantea Mitchell (2005), que no existen medios visuales. Desde esta perspectiva, la imagen no puede ser separada del lugar y las condiciones de su aparición, ni de los elementos que la acompañan y la complementan, así, existe un complejo de relaciones que configuran el sentido de la imagen. A su vez, las imágenes materializan una forma visible del tiempo y, por tanto, de las formaciones culturales de este. Lo anterior sugiere analizar las imágenes en sus relaciones, "en los sistemas de valores e ideologías que contienen las sociedades" (Contreras, 2017, p. 486).

De acuerdo con la concepción de visualidad y fotografía expuesta, el trabajo de investigación planteó tres momentos de análisis. El primero de ellos tiene relación con la identificación de los temas propios de un periodo histórico. En este sentido, el periodo de análisis escogido (2010-2014) se puede caracterizar por una serie de hechos relacionados con la configuración y con la visibilización del sujeto víctima. Entre ellos, podemos enumerar la expedición de la Ley 1448/2011, de 10 de junio, ${ }^{2}$ el inicio de los diálogos de paz con las FARC en 2012 y la publicación por parte del CNMH del informe ¡Basta ya! Colombia: memorias de guerra y dignidad en 2013, que tuvo como objetivo colaborar con la reconstrucción de la memoria de la violencia política en el país, centrándose en las víctimas. Finalmente, 2014

2 Es importante apuntar que la Ley 1448/2011, de 10 de junio emerge como resultado de una serie de disputas y discursos en torno a las víctimas. Como se apunta en páginas anteriores, en 2005, ya se había promulgado la Ley $975 / 2005$, de 25 de julio. Estas leyes demuestran cómo se va estableciendo una serie de enunciados que coadyuvan a la emergencia de una serie de prácticas discursivas y no discursivas, pero que se refieren a una serie de movimientos y disrupciones en los enunciados sociales que coadyuvan a la formación de regímenes visuales.

14 Las imágenes de las víctimas del conflicto armado en la revista Semana... - Dixon Vladimir Olaya Gualteros 
es importante por la contienda por la Presidencia de la República. En este contexto, los discursos acerca de la continuidad de los diálogos de La Habana o el viraje hacia la restitución y actualización de la Política de Defensa y Seguridad Democrática cobrarán relevancia. En ellos las víctimas van a ser tanto objeto de discusión como un agente político importante para mediar en el sentido de estos discursos.

El segundo nivel de análisis hace referencia al estudio morfológico de las fotografías y sus relaciones con los artículos que las acompañan. Se trata de una mirada a los objetos de la imagen, sus temas iconográficos, los enfoques, los encuadres, la luz y las relaciones entre los diversos elementos que componen la imagen. Estos elementos permiten identificar temas y subtemas de las fotografías, además el lugar del ver que enmarca la imagen para el espectador. Al tiempo se observan las relaciones entre las imágenes y los artículos que acompañan en pro de evidenciar la manera en que estas interrelaciones coadyuvan a generar marcos de interpretación.

El tercer nivel de análisis, siguiendo a Bal (2005), se direcciona a la identificación de las relaciones entre las imágenes y los significados culturales y discursivos de una época. Se trata de observar la forma en que estas, por medio de la luz y el color, generan una señal-espacio, una visualidad, que incorpora, hibrida y condensa las formas de lo cultural y lo político.

Es importante mencionar que la investigación analizó más de 258 artículos e imágenes que aparecieron en la revista Semana en el periodo mencionado. Los artículos y las fotografías fueron seleccionados por su referencia a víctimas y victimarios. El análisis dejó ver que la mayor cantidad de artículos y fotografías referidas a los actores del conflicto se presentaron en 2010, 2011 y 2013, privilegiando mujeres y niños.

Ahora bien, para este artículo, se decidió seleccionar cuatro fotografías que representan un nivel de recurrencia en las series estudiadas y que además se encuentran relacionadas con acontecimientos importantes de la dinámica de la violencia. En este sentido, la fotografía 1 hace referencia a un hecho importante para la política y el enfrentamiento a las FARC, a saber, la muerte del Mono Jojoy. Las fotografías 2 y 4 se refieren a lo que se 
denominó en Colombia falsos positivos, hecho que tuvo una especial relevancia por lo que significaba la visibilización de un modo de operar en el conflicto. Sin embargo, es importante mencionar que cada una de estas dos fotografías se refieren a sujetos víctimas diferentes. La fotografía 2 tiene su centro en niños, sujeto que cobra una especial relevancia tanto para los artículos de la revista Semana como para lo que significa para la sociedad que ellos estén inmersos en la dinámica de la guerra. La fotografía 4 se refiere a madres de víctimas del conflicto, que no fueron afectadas en su corporalidad, pero son símbolos de la forma en que la guerra afecta a diversos segmentos de la población.

Diferente de la fotografía 2, la fotografía 3 se focaliza en una anciana cuyo cuerpo fue vulnerado por integrantes de las FARC. Su presencia nos habla de una víctima directa, la que nos ayuda a reconocer una variación en las características de los sujetos víctimas, aunque, como demuestra este trabajo, la lógica de la enunciación y visibilización de las víctimas puede contener lógicas similares. En este sentido, las imágenes aquí presentadas se comprenden, como lo enuncia Bal (2005), como un detalle de un conjunto total de series o del mundo social en el que este funciona y que dicen de los acontecimientos de un modo provisional y estratégico.

\section{Víctimas y victimarios: abstracción y levedad}

En 2011, como ya fue enunciado, fue dado de baja el Mono Jojoy. Para esta ocasión, la revista Semana, a través de una edición especial, despliega una serie de artículos en los que habla no solo de este personaje, sino del Gobierno y de su lucha contra la violencia en el país. Si bien las imágenes a las que se refieren estos artículos no presentan de manera directa a la víctima, plantean la lógica desde la que, para la época, se veía y se comprendía el otro oponente y que marca los modos en los que se incluirá la aparición de la víctima desde el medio de comunicación.

En un artículo publicado en la edición 1482, denominado "Golpe al terror" (Semana, 2010c), se construye una composición de cuatro fotogradfías que llenan dos páginas centrales de la revista Semana y en las que se hace referencia a la muerte del Mono Jojoy. En la fotografía ubicada en 
la parte superior izquierda, se presenta la imagen del cuerpo sin vida del entonces uno de los líderes de las FARC (fotografía 1). Desde un ángulo picado, se nos muestra un rostro borroso, un cuerpo envuelto y amarrado en un papel de color café, en sustitución de las sábanas blancas utilizadas comúnmente en la presentación y el cuidado de los muertos. Dicho papel adquiere la forma de bolsas, por las cuerdas que parecen cerrar y delimitar algunas partes del cuerpo. A su vez, el material que acabamos de describir aparece teñido de sangre. Si bien los amarres que nos deja ver la fotografía delinean las partes del cuerpo, el tronco y las piernas no tienen la forma común en la que figuramos un ser humano. Al tiempo, no tenemos claridad de la posición de los brazos, vemos algo que parece serlo, pero no se encuentran relacionados con sus características habituales. Al parecer, han sido amputados. En suma, tenemos la figuración de un cuerpo humano cercano a lo extraño. Además, el cuerpo sin vida aparece sobre una bandeja plateada, característica de centros hospitalarios y no la tradicional cama o féretro sobre la que honramos a los muertos. Todo lo que compone la fotografía nos lleva a un lugar del extrañamiento. No tenemos un cuerpo, tenemos sus vestigios, nos encontramos ante la deformación. Existe la exposición de algo que registra y eterniza la acción de las fuerzas militares colombianas, pues parecen haber acabado, según el artículo que acompaña la imagen, con algo que sobrepasa y afecta lo humano: "el terror". Se nos presenta lo monstruoso, pues evidenciamos "un orden distinto al más probable" (Canguillen, 1992, p. 33), lo que afecta las formas de concebir al otro y genera una significación, pero a la vez posibilita la negación de su presencia.

\section{Fotografía 1. "Golpe al terror"}

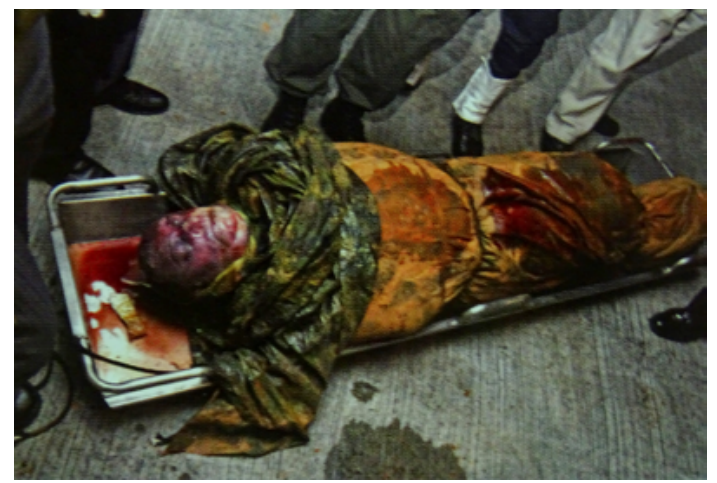

Fuente: Semana (2010). 
En relación con lo expuesto, en nuestro país no es mucho lo que sabemos y encontramos acerca de las fotografías de los muertos o post mortem. Pareciera que esta práctica no es habitual y en muchos casos poco valorada, pero a la vez también nos habla de una significación cultural relacionada con la negación de la muerte (Henao, 2013). En este sentido, la visibilización de la fatídica muerte del Mono Jojoy, en un medio de comunicación tan importante como la revista Semana, conlleva una afrenta a una sensibilidad construida culturalmente y en la que los modelos de juventud y belleza conducen a ocultar la muerte, relegarla a los cementerios o, como en este caso, servirse de ella como espectáculo. En este sentido, la muerte es instrumentalizada, casi como un ejercicio moral de interpelación a la subjetividad a través de un modo de juzgamiento a una conducta que socialmente no es aprobada. A su vez, siguiendo a Barthes (1990), podríamos señalar que la figura de una muerte siniestra es la imagen viva de una cosa muerta que coadyuva a su remembranza, tensionando, al tiempo, valores culturales de la iconografía cristiana, tan adherida a nuestra cultura, en la que la belleza física era cercana a la perfección moral.

Otro elemento que coadyuva a la construcción de ese otro, desprovisto de humanidad, tiene que ver con lo que rodea el cuerpo del Mono Jojoy. Él se ve rodeado de pies, lo que nos ayuda a pensar que se encuentra a ras de piso. Un cuerpo tendido, despreciado, solo, sin que se nos permita intuir deudos que testifiquen el dolor. Solo existen quienes observan el cuerpo gris, yermo, lo que dice de una muerte sin dignidad.

Además, el artículo denominado "Golpe al terror", que ayuda a leer la imagen antes descrita, se sostiene sobre un solo argumento, a saber, la "difícil" e inteligente tarea de las Fuerzas Armadas por acabar con el jefe de las FARC, y quien, según el mismo medio de comunicación, "se había convertido en el 'coco' de los colombianos. Con un bombardeo intenso lograron vulnerar las defensas de Jojoy [... Por primera vez, un miembro del Secretariado moría en territorio colombiano no por vejez o enfermedad, sino por la acción del Estado" (Semana, 2010c).

La imagen que hemos descrito ayuda a mostrar la labor cumplida por el Ejército y el cuerpo maltrecho es el trofeo. A la vez, el discurso utilizado 
da cuenta de la magnitud del evento, su dificultad y, asimismo, la forma en que el Gobierno de turno lleva acabo una lucha sin cuartel contra años de terror infringido por el grupo armado. El artículo pone en el lugar de poder al Ejército y al Gobierno a través de la visibilización de lo que estas instituciones son capaces de hacer, lo que implica también una posición de subordinación ante estas instituciones, mientras que al otro, al oponente, en contenedor del horror, despolitizando de esta forma años de conflicto armado. En este orden, la imagen construye formas de interpelación que tienen relación con la construcción del miedo, al tiempo que la utilización de semas culturales que son cercanos a la experiencia sensible de los sujetos en una época. Nótese, a su vez, que la victimización es el eje a través del cual se construye al héroe y al victimario (las FARC). Así, imagen y discurso constituyen un marco interpretativo para enunciar las dinámicas del conflicto, pero simultáneamente una suerte de ética en la que el opositor es posible de ser humillado y desaparecido.

Si bien las imágenes y el discurso no referencian víctimas, sí nos advierten del modo en que ella es puesta en el escenario público, en tanto agente sobre el que se movilizan otros actores. Por un lado, quien lo victimiza, y por el otro, quien salvaguarda sus derechos. De este modo, la víctima no es un sujeto de discursividad o visibilidad, sino que es el eje para la legitimación o deslegitimación de una serie de prácticas sociales por parte de unos actores particulares.

En algunos artículos de la revista Semana, la imagen de la víctima es referenciada de manera concreta, pero ella, en la misma lógica antes enunciada, construida desde semas que tienen que ver con la sensibilidad y la experiencia cultural de un momento particular en nuestros contextos sociales sin que ello signifique su valoración como sujeto político o que su aparición permita algún tipo de interpelación al mundo de lo social. Así, por ejemplo, para 2010, en la revista Semana es publicado un artículo titulado los "Los casos olvidados de los falsos positivos" (2010a). En él encontramos una secuencia de imágenes en las que se figuran, por lo que dice el pie de página, y también el contenido interior del artículo, que son niños utilizados para presentarlos como combatientes de las FARC dados de baja en 
combate (fotografía 2). A los niños, los ojos les son tapados con una franja negra, con la que se trata, por una norma-ley de la época, de cubrir y respetar la identidad de los menores de edad. No obstante, como veremos más adelante, el que sean niños solo se convierte en un recurso para pensar en lo macabro de los victimarios, en este caso militares pertenecientes al Ejército Nacional de Colombia.

Lo que se resalta en las imágenes de la revista Semana, para lo que denomina un informe especial, es el cuerpo muerto, que figura la acción del otro, la del victimario. Los cuerpos son mostrados en diferentes posiciones, en ambientes rurales, pero siempre llenos de sangre, lo que indicaría, mucho más que la subjetividad de aquel que llamamos niño, el rastro de la afectación en el cuerpo del otro. Las imágenes nos ubican de frente a los cuerpos desplegados sobre superficies aciagas. El lugar en el que nos ubica la imagen es ante el resto de algo que en algún momento tuvo vida, precipitado sobre la tierra, acompañado de un arma que dice lo que fue. Ello no borra que aquello a que se alude fue construido por lo malévolo: un inocente puesto en el lugar de un combatiente. ${ }^{3}$ La fotografía nos lleva a la culminación de una acción, el resultado de un hecho perpetrado por alguien. La imagen conlleva la constitución de un estado que no es el de la pura contemplación, sino la del asombro, la de ver lo siniestro.

\section{Fotografía 2. "Los casos olvidados de los falsos positivos"}

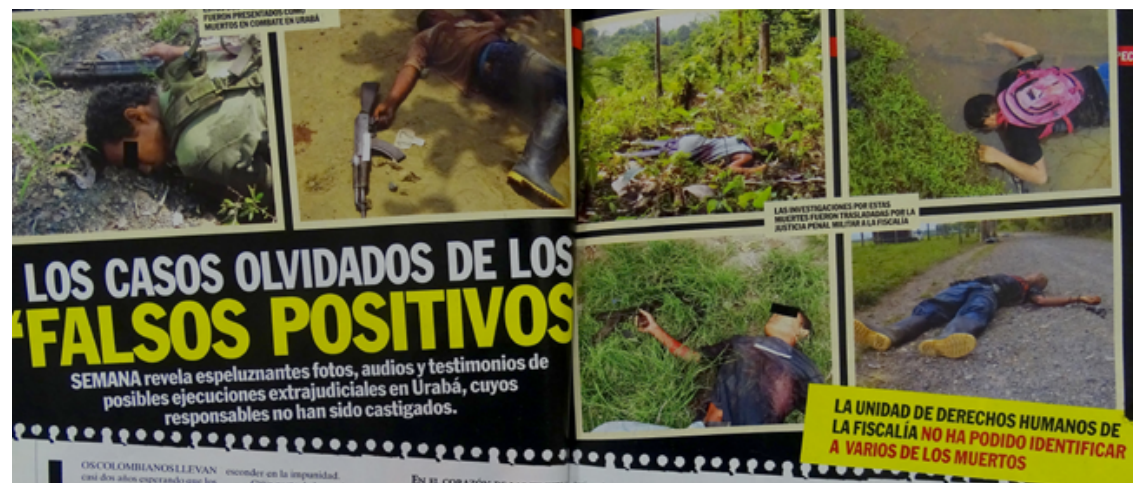

Fuente: Semana (2010a).

3 Si bien se podría aludir que las fotografías tratan de caracterizar los errores de quienes señalaron a estas víctimas como combatientes, ellas mismas siguen visibilizándolos como parte de los combates. 
La idea antes expuesta es complementada por los pies de página que acompañan a las fotografías en las que se enuncia: "Estos dos menores de edad fueron presentados como muertos en combate" $y$ "las investigaciones por estas muertes fueron trasladadas por la justicia penal militar a la fiscalía”. En las dos alusiones, no se habla de los niños, sino que la acción siempre recae en otros. La idea de niño tan solo cobra valía en el peso que tienen en lo social las acciones de quienes realizan la afectación y sobre quien quiere resarcirlo. De este modo, se enjuicia a quien es capaz de afectar a aquel personaje que en nuestra cultura ha adquirido un valor cercano a la ingenuidad, la inocencia, digno de protección, sujeto de derechos, relacionado con el juego y la educación. Así, la narración de la afectación a un cuerpo de este talante simbólico coadyuva a construir el dramatismo, y amplía para su visibilización lo siniestro del victimario, aunque este sea abstracto, casi fantasmal, a pesar de que se nombren personajes, pues el artículo, como en una suerte de obra abierta, siempre deja en suspenso los móviles del asunto.

La imagen del victimario se construye en la relación discurso-imagen, en el sentido de romper aquello que en lo social, e incluso en la experiencia sensible de los sujetos, debería ser infranqueable. Desde este ángulo, la fotografía de la víctima aparece como una verberación del acontecimiento. La imagen es el testimonio del suceso, la discursividad es aquello que la explica, y ambas constituyen elementos simbólicos que se dirigen al corazón de la experiencia sensible de los individuos de una época. Ella, la imagen, como lo plantea Crary (2008), dirige una surte de fijación hacia algo. La fotografía posibilita el juego de absorción del espectador, aunque al tiempo propone la ausencia de la víctima.

El reforzamiento del poder del victimario no posibilita la construcción de la identidad del sujeto víctima, pues ella carece de una narrativa. No hay una oposición entre quién hace o comete la acción y sobre quién recae esta. El victimario es la sinrazón y a través de ella se promueve el miedo, pues la acción se efectúa sin que medie algún tipo de valoración social, cultural, religiosa o política. El victimario es una individualidad regida por el caos. El cuerpo del caído es el hecho que nos conduce a ver los modos del actuar del asesino en una suerte de extimidad, como diría Sibilia (2008), 
de la privacidad del acto de dar muerte. En antítesis, el Estado, el cuidador maniobra de diferentes maneras, intenta detener el caos, a pesar de estar imbricado en los hechos, y eso le procura algún tipo de legitimidad en lo social. Lo anterior, por demás, invisibiliza el trabajo de denuncia que llevaron a cabo, para el esclarecimiento y la visibilización de estos hechos, las madres de los afectados.

La manera en que, como lo plantea Didi-Huberman (2014), el pueblo, la sociedad civil, en este caso niños, son expuestos, es porque ellos están amenazados, no solo como víctimas, sino como representación. Son llamados a la figuración en su desaparición. Este elemento no es de menor importancia, pues la forma en que son exhibidos desvela una construcción cultural en la que los sujetos se encuentran en medio de la figuración de otros, sin ser un tamiz de colores del mundo de la violencia, sino eje desde el que se desprende el enfrentamiento.

En una lógica parecida, la construcción de un cuerpo que materializa el dolor, y en la que se homogeneiza el sujeto víctima, desalojando su voz, su experiencia, son ejemplificantes algunas imágenes y artículos que aluden a la mujer como víctima. En un artículo llamado "Los abusos de la guerra” de José Alejandro Castaño (2010), la primera imagen con la que se encuentra el observador es la de una mujer anciana, al lado de otra imagen que hace alusión al conjunto de su familia (fotografía 3). Ella no mira hacia la cámara, sino que parece tener la mirada perdida, la que además es vidriosa y sirve como elemento simbólico referido a la tristeza y el dolor. Ella es sinónimo de un tiempo pasado, significado que es construido a través de la relación que es posible erigir por el desgaste que encarna su cuerpo, pero también por el modo en que aparece atada a una generación que la antecede y que es figurada a través de la fotografía que la acompaña. Lo anterior es reforzado por el subtítulo del artículo y el pie de página que coadyuvan a construir el sentido de la imagen:

\section{Subtítulo}

Por venganza, escarmiento o simple crueldad, muchas mujeres han sido violadas en medio del conflicto. La mayoría guarda silencio. Quienes denuncian, reciben poco apoyo. 
Pie de foto

Doña María, de 87 años, no solo tuvo que ser testigo de la muerte de su hijo, fusilado por la guerrilla, sino que hace dos años ella misma fue víctima de vejámenes sexuales cometidos por un soldado.

El plano construido para la visibilización de la mujer no permite verla en su contexto. Existe un aislamiento de la mujer, pero al tiempo una focalización en sus detalles, lo que coadyuva a centrar la mirada en lo sensible y que al tiempo potencia los semas que ella contiene históricamente: madre, hermana, esposa, abuela. Tal estrategia guarda coherencia con la pretensión de la totalidad del artículo: contar la forma en que distintas mujeres han sido violentadas en medio de la guerra. Pese al supuesto objetivo del artículo (desvelar lo particular de la experiencia de diferentes mujeres en la guerra), la estructura de todas las narrativas es la misma: la manera en que son tratadas y vulneradas, la humillación y degradación en su condición de ser mujeres. Así, las mujeres, presentadas en el artículo, son negadas en su diferencia, sustraídas de una experiencia única, con lo que enfrentan el presente desde condiciones particulares.

No obstante, habría que señalar que la sola referencia a la imagen no nos conduciría a ver a un cuerpo violentado. Aun así, en tanto cuerpo, la mujer que ocupa la imagen da cuenta de una experiencia vivida, es recuerdo, es la coexistencia de una suerte sucesos. Al hacer a la vejez presente en la imagen, desvela un pasado encarnado que pervive en el presente, pero que, a la vez, en nuestra cultura, es un estado que se encuentra ligado a la pérdida, al deterioro, a la vulnerabilidad, comparado con otros grupos etarios, pero también es sintomático de cercanía a la muerte y por ello con la necesidad de ser cuidada. Este referente simbólico que se promulga a través de diversas instituciones en nuestra sociedad conlleva que la violencia ejercida sobre esta subjetividad cobre en un conflicto armado dimensiones que sugieren la idea del horror, comprendido este como un tipo de experiencia capaz de desestabilizar, no solo una serie de condiciones físicas, sino de universos valorativos desde los que construimos unas prácticas sociales (Broullón y Velazco, 2012). Es en este sentido que la narrativa y la imagen nos interpela, pues alude a la fractura de un tipo de sema que se 
debe respetar. Es decir, no es solo la violencia, es a quién se le realiza y que comprueba una suerte de escisión con un cúmulo de significaciones sociales que nos sitúan, como espectadores, en la incertidumbre, y así deja una suerte de vacío de sentido.

Al tiempo, tanto la imagen como el texto que la acompaña se constituye en el congelamiento del sujeto y le da una identidad, atrapada en un espacio-tiempo particular que se sostiene en el trauma, aunque el devenir del tiempo haya coadyuvado a la víctima a construir instrumentos para enfrentar el efecto de los eventos atroces. Este tipo de nombramiento contribuye a generar comunidades de resentimiento, pues quedarse en el pasado, como lo sostiene Das (2008), puede conducir a no reconocer a los individuos y con ello a no comprometerse con la construcción del yo en el presente.

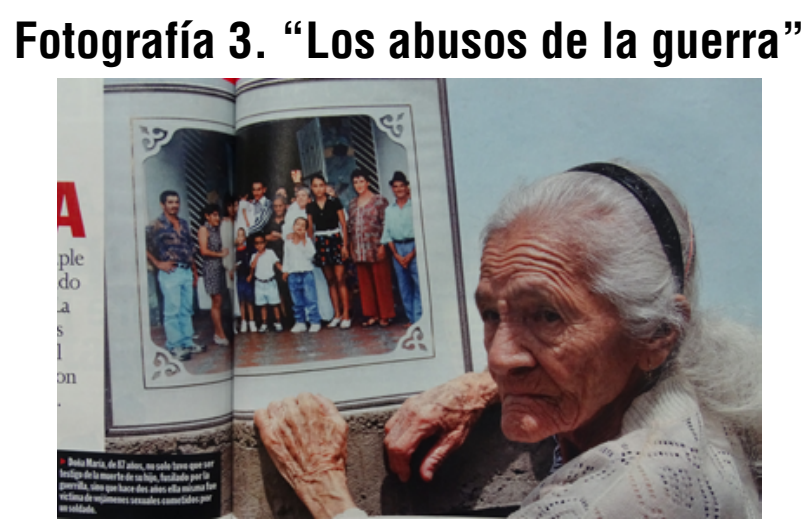

Fuente: Castaño (2010).

En esta perspectiva, también se encontraron, en medio de procesos de diálogo entre el Gobierno y las FARC, ejercicios de memoria, imágenes y anuncios, casi publicitarios, que construyen a la víctima como cuerpos sobrecogidos, derrumbados, como una suerte de residuo de vida (fotografía 4). Así, por ejemplo, en la imagen que encontramos en la publicación de la revista Semana de la edición 1621 de mayo de 2013, se presencia una mujer sostenida por dos representantes de la institucionalidad (Cuerpo Técnico de Investigación [CTI]), pero cuyo título conlleva ver a los victimarios. 


\section{Fotografía 4. ¿Sabe cuál es la causa de su dolor?}

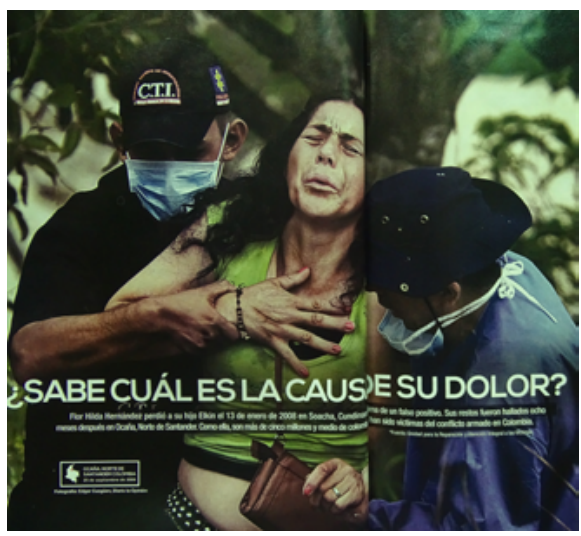

Fuente: Semana (2013).

El plano deja ver la acción de los individuos que se encuentran ayudando a una mujer. Para el espectador, es la destrucción del sujeto, pero su vida, su resistencia, su búsqueda y los desarrollos que realizaron las madres de los desaparecidos de Soacha, a los que alude la página en la que se encuentra la fotografía, no son connotados. Lo que hay es el momento de la muerte. La fotografía nos envía a la falta de palabra, a la ausencia de sujeto a través de su invisibilización como actor y agente del esclarecimiento de hechos violentos.

Como es posible evidenciarlo, este tipo de imágenes nos conducen a la reducción de la alteridad, pero en cambio apoya un concepto que, como lo plantea Butler (2014), es un estereotipo y a la vez una construcción política en torno a la feminidad y a la masculinidad; "los hombres son inmunes e inviolables, mientras con las mujeres sucede lo reverso” (p. 56). Así se extiende y robustece una significación cultural que conduce al olvido, a la desmemoria, pues la vulnerabilidad de los sujetos mujeres se ha hecho, en algún sentido, casi natural.

Ahora bien, en la construcción de un sujeto sin voz, es detectable un espectáculo, un humanismo de la miseria. Una mirada, quizá, un poco más responsable pudiera construirse desde el devenir de los seres humanos, sobre sus pasajes, sus tránsitos. Lo anterior no quiere decir que olvidemos los momentos de tragedia y decaimiento, pero ello no lo es todo, somos en el 
cambio y en el trasegar, en las formas de experienciar los acontecimientos. Elementos que parece olvidar este tipo de imágenes y artículos que, en muchos de los casos, se quedan tan solo con el derrumbe como elemento para mostrar y posicionar al otro, víctima, ante los fenómenos sociales.

\section{Conclusiones}

En las imágenes presentadas, lo sensible es un marco de gran importancia para la construcción de la significación de lo social, de lo político, de la guerra, pero también de lo humano mismo. Desde ellas, se constituyen visibilidades que hablan del horror y que son inmovilizadoras. En estas construcciones, las relaciones que se plantean son estáticas, las identidades están suspendidas y no dan cuenta de los espacios y de los tiempos, por lo que entierran la historia. Nos encontramos con narrativas con un fuerte presentismo e inmediatez que no abogan por una relación entre los diferentes registros temporales en las que existen y se forman los sujetos. Además, las imágenes y las narrativas que las acompañan sobre el conflicto armado perturban preconcepciones y creencias sociales y personales sobre fenómenos y sujetos, por lo que fuerzan a los espectadores a reconsiderar o construir ciertas significaciones.

Una visión distinta, creemos, haría que el sujeto víctima tuviese una historia que posibilitara sacarlo del poder masificante de la igualdad y lo inmunizara de su homogeneización. No obstante, es claro que los medios de comunicación, y para este caso particular la revista Semana, caracterizan a los sujetos, les dan unas cualidades, pero estas no lo descubren, son dadas para diferenciarlos en su destino de ser sacrificados, no necesariamente para reconocerlos (Gutiérrez y Lewkowics, 2005). La caracterización del sujeto, no su reconocimiento, solo lo deja ver como blanco de la violencia, al tiempo que instituye la culpabilización del victimario, lo que guarda coherencia, y no es una simple coincidencia, con la forma en que es comprendido el conflicto desde las leyes que supuestamente se configuraron para resarcir las víctimas.

Los artículos demuestran, al tiempo, que solo hay un reconocimiento desde el Estado y no desde los sujetos mismos, pues tal institución es 
la que representa a los distintos grupos sociales, a los que hace referencia en tanto han sido vulnerados sus derechos. Así, la identidad sufriente sirve como instrumento. El sujeto es definido por las políticas del Estado, y es ello lo que tenemos para la memoria, a través de los medios de comunicación. Es una memoria de la victimización, lo que, a su vez, aunque suene paradójico, es una memoria para el olvido, pues lo que se ha infringido es lo que precisamente se busca olvidar para el perdón y el restablecimiento de las relaciones en lo social. No se procura una imagen, ni una memoria de los sujetos que coopere con la comprensión de las complejas dinámicas de las que emergen los sujetos víctimas.

\section{Referencias}

Audiencia general de medios. (s. f.). Recuperado de https://www.aimc.es/ egm/datos-egm-resumen-general/

Bal, M. (2005). El esencialismo visual y el objeto de los estudios visuales. Comunicación y Medios, 16, 45-68. Recuperado de https://comunicacionymedios.uchile.cl/index.php/RCM/article/view/11547

Barthes, R. (1990). La cámara lúcida: nota sobre la figura. Barcelona, España: Paidós.

Broullón Lozano, M. y Velasco Padia, P. (Coords.) (2012). La representación del horror: semiótica, estética y estudios culturales. Madrid, España: Ápeiron. Estudios de filosofía.

Butler, J. (2014). Vida precaria, vulnerabilidad ética. En B. Saez Tajafuerce (Ed.), Cuerpo, memoria y representación: Adriana Cavarero y Judith Butler en diálogo (pp. 47-80). Barcelona, España: Icaria.

Canguilhem, G. (1992). La monstruosidad y lo monstruoso. Medellín, Colombia: Universidad Nacional de Colombia. 
Castaño, J. A. (2010, agosto 7). Los abusos de la guerra. Semana. Recuperado de https://www.semana.com/nacion/articulo/los-abusosguerra/120277-3

Centro Nacional de Memoria Histórica. (s. f.). Base de datos ;Basta ya! Recuperado de http://www.centrodememoriahistorica.gov.co/micrositios/informeGeneral/basesDatos.html

Conteras, F. (2017). Estudio sobre los planteamientos teóricos y metodólogicos de los estudios visuales. Arte, Individuo y Sociedad, 29(3), 483-499. DOI: https://doi.org/10.5209/ARIS.55559

Crary, J. (2008). Suspensiones de la percepción: atención, espectáculo y cultura moderna. Madrid, España: Akal.

Das, V. (2008). Trauma y testimonio. En F. Ortega (Ed.), Veena Das: sujetos del dolor, agentes de dignidad (pp. 149-165). Bogotá, Colombia: Universidad Nacional de Colombia.

Dewey,J. (2008). El arte como experiencia. Buenos Aires, Argentina: Paidós.

Didi-Huberman, G. (2014). Pueblos expuestos, pueblos figurantes. Buenos Aires, Argentina: Manantial.

Fontocuberta, J. (2002). El beso de Judas: figura y verdad. Barcelona, España: Gustavo Gili.

Foucault, M. (1992). La verdad y las formas jurídicas. Barcelona, España: Gedisa.

Gutiérrez, C. y Lewkowics, I. (2005). Memoria, víctima y sujeto. Revista de Ciencias Sociales, 36(23), 9-22.

Hartog, F. (2012). El tiempo de las víctimas. Revista de Ciencias Sociales, $44,12-19$. 
Henao Albarracín, A. M. (2013). Usos y significados sociales de la figura post morten en Colombia. Universitas Humanística, 75, 329-355. Recuperado de http://www.scielo.org.co/pdf/unih/n75/n75a14.pdf

Herrera, M. C. y Pertuz, C. (2015). Narrativa testimonial y memoria pública en el contexto de la violencia política en Colombia. Kamchatka, 6, 913-940. DOI: https://doi.org/10.7203/KAM.6.7684

Huyssen, A. (2001). En busca del futuro perdido: cultura y memoria en tiempos de globalización. Buenos Aires, Argentina: Fondo de Cultura Económica.

Ley 975/2005, de 25 de julio, por la cual se dictan disposiciones para la reincorporación de miembros de grupos armados organizados al margen de la ley, que contribuyan de manera efectiva a la consecución de la paz nacional y se dictan otras disposiciones para acuerdos humanitarios.

Ley 1448/2011, de 10 de junio, por la cual se dictan medidas de atención, asistencia y reparación integral a las víctimas del conflicto armado interno y se dictan otras disposiciones.

Mandoki, K. (2006). Estética cotidiana y juegos de la cultura. Ciudad de México, México: Siglo XXI.

Mirzoeff, N. (2015). Cómo ver el mundo: una nueva introducción a la cultura visual. Barcelona, España: Paidós.

Mitchell, W. J. (2005). No existen medios visuales. En J. L. Brea (Coord.), Estudios visuales: la epistemología de la visualidad en la era de la globalización (pp. 5-14). Madrid, España: Akal.

Niedermair, A. (2013). La distribución de lo inteligible y lo sensible hoy. Cuadernos del Centro de Estudios en Diseño y Comunicación, 43, 33-51. Recuprado de https://fido.palermo.edu/ 
servicios_dyc/publicacionesdc/vista/detalle_articulo.php?id_ articulo $=8651 \&$ id_libro $=407$

Semana. (2010a, julio 17). Los casos olvidados de los "falsos positivos. Recuperado de https://www.semana.com/nacion/articulo/los-casos-olvidados-falsos-positivos/119416-3

Semana. (2010b, septiembre 27). Qué tan cerca está el fin. Edición Especial, La muerte del mono Jojoy, pp. 26-30.

Semana. (2010c, septiembre 9). Golpe al terror. Semana. Recuperado de https://www.semana.com/nacion/articulo/golpe-terror/122474-3

Sibilia, P. (2008). La intimidad como espectáculo. Buenos Aires, Argentina: Fondo de Cultura Económica.

Unidad de Víctimas. (2019, abril 1). Víctimas del conflicto armado. Recuperado de https://cifras.unidadvictimas.gov.co/Home/Desplazamiento

Yepes Muñoz, R. D. (2014). El escudo de Atenea: cultura visual y guerra en Colombia. Cuadernos de Música, Artes Visuales y Artes escénicas, 9(2), 23-43. DOI: https://doi.org/10.11144/Javeriana.mavae9-2.eacv 